\title{
O PIBID NO BOJO DAS POLÍTICAS EDUCACIONAIS DE FOR- MAÇÃO DE PROFESSORES
}

\author{
THE PIBID WITHIN THE SCOPE OF EDUCATIONAL POLICIES ON TEACHER \\ TRAINING
EL PIBID EN EL CENTRO DE LAS POLÍTICAS EDUCACIONALES DE LA FOR- MACIÓN DE LOS PROFESORES

\author{
Josiane Lopes Medeiros \\ Instituto Federal de Educação, Ciência e Tecnologia Goiano. \\ Câmpus Rio Verde - GO. \\ jozymedeiros@gmail.com \\ Luciene Lima de Assis Pires \\ Instituto Federal de Educação, Ciência e Tecnologia de Goiás. \\ Câmpus Jataí - GO \\ lucieneapires@gmail.com
}

\begin{abstract}
RESUMO: Este trabalho aborda as políticas educacionais para a formação de professores no Brasil desde o final do século XX, mais precisamente na década de 1990, verificando a propositura para a formação de professores. Em especial, analisam-se as implicações do Programa Institucional de Bolsa de Iniciação à Docência (Pibid) para a formação docente. Para tanto, realizou-se revisão bibliográfica e análise de legislações como a Constituição da República Federativa do Brasil; LDB n 9.394/1996; Lei no 10.172/2001; Plano de Desenvolvimento da Educação (PDE)/2007; Decreto $n^{\circ}$ Lei 6.094/2007; Plano de Ações Articuladas/2007 e o Pibid bem como o aporte teórico de Freitas (2002); Imbernón (2004); Saviani $(2008,2009,2010)$ e Sheibe (2002). Verificou-se que as leis que regulamentam a formação de professores no Brasil constituem processos de mudanças e descontinuidade, o Pibid é compreendido pelas políticas públicas como forma de valorização docente e iniciativa para a formação inicial e continuada, porém, a análise crítica é imprescindivel à qualidade das ações, principalmente das ações educativas. Sendo assim, é importante uma avaliação atenta do Pibid e sua articulação com a valorização dos profissionais da educação e proposição de novos rumos para a Educação Básica.
\end{abstract}

PALAVRAS-CHAVE: Pibid. Políticas Educacionais. Formação de Professores. PNE.

ABSTRACT: This paper discusses the educational policies for teacher training in Brazil since the late twentieth century, more precisely in the 1990 s, analysing for the training of teachers. We analyze, in particular, the implications of the Institutional Program of Teaching Initiation Scholarship (Pibid) for teacher training. To do this, we performed a literature review and analysis of laws such as the Constitution of the Federative Republic of Brazil; LDB (Brazilian Education Basic Tenets Law) 9.394/1996; Law 10.172/2001; Education Development Plan (PDE)/2007; Decree-law 6.094/2007; Articulated Actions Plan/2007 and Pibid, as well as the theoretical bases of Freitas (2002); Imbernón (2004); Saviani (2008, 2009, 2010) e Sheibe (2002). It was found that the laws regulating the training of teachers in Brazil express processes of change and discontinuity, the Pibid is an public policy understood as a way of teacher appreciation and initiative for an education inicial and continuing; however, critical analysis is essential to the quality of actions, mainly the educational actions. Therefore, it is important to assess carefully the Pibid as a whole and its articulation with the enhancement of the educational professionals, and propose new directions for basic education.

KEYWORDS: Pibid. Educational policies. Teacher training. PNE.

RESUMEN: Este trabajo aborda las políticas educacionales que contribuyen a la formación de los profesores en Brasil desde el final del siglo XX, más precisamente en la década de 1990, investigando la proposición en relación a la formación de profesores. En particular, se analiza las implicaciones del Programa Institucional de Beca a la Iniciación de la Docencia (PIBID) en la formación docente. Para tanto, se realizó una revisión bibliográfica y se ha hecho un análisis de leyes como: la Constitución de la República Federativa de Brasil; LDB 9.394/1996; Ley 10.172/2001; Plan de Desarrollo de la Educación (PDE)/2007; Decreto Ley 6.094/2007; Plan de Acciones Articuladas/2007 y el PIBID, habiendo tenido como contribución teórica: Freitas (2002); Imbernón (2004); Saviani $(2008,2009,2010)$ y Sheibe (2002). Se ha comprobado que las leyes que regulan la formación de los profesores en Brasil constituyen procesos de cambios sin continuidad, el PIBID es comprendido por las políticas públicas como una manera de valorización docente y también una iniciativa para la formación inicial y continúa, sin embargo, un análisis crítico es imprescindible a la cualidad de las acciones, principalmente las acciones educativas. Así siendo, es importante una evaluación muy atenta del PIBID en su totalidad, especialmente su articulación respecto a la valorización de los profesionales de la educación así como su proposición en la dirección de los nuevos rumbos a la Educación Básica (en Brasil).

PALABRAS CLAVE: PIBID. Políticas Educacionales. Formación de los Profesores. PNE

$\overline{\text { Artigo recebido em maio de } 2014}$

Aprovado em julho de 2014

Cad. Pes., São Luís, v. 21, n. 2, mai./ago. 2014 


\section{1 | Introdução}

No Brasil, a história das políticas educacionais, revela que ao longo do tempo, as medidas tomadas priorizam e servem, sobretudo, a propósitos econômicos em detrimento de outros setores da sociedade. A luta dos educadores por uma educação pública de qualidade, que começou na década de 1920, permanece até este início de século como "forma de resistência às políticas e reformas em curso e na reivindicação por melhores condições de ensino e de trabalho para os profissionais da educação." (SAVIANI, 2009, p. 32).

No final da década de 1990 e início do século XXI, presenciamos avanços e iniciativas na área da educação e do ensino. Porém, no que se refere à formação de professores, muitas destas políticas tiveram origem em acordos políticos com interesses locais, regionais e, às vezes, até pessoais ou de uma minoria que em nome do desenvolvimento adéquam setores da sociedade em prol de seus benefícios, interessadas no capital.

Dentre as políticas implementadas nos últimos anos, o Pibid se estabelece a partir de 2007 , com o propósito de efetivar melhoria na formação inicial e continuada dos professores da educação básica e atender a falta de profissionais para trabalhar com disciplinas específicas. Diante disso, analisa-se a propositura das políticas educacionais de formação de professores no Brasil, desde a década de 1990 e as implicações do Pibid inserido nas políticas públicas de formação docente, Para tanto, na análise da propositura das políticas educacionais e as implicações do Pibid na formação de professores, buscou-se os princípios da abordagem qualitativa, utilizando-se de revisão bibliográfica e análise da legislação vigente.

Como pesquisa bibliográfica, este estudo contemplou a formação de professores desde o final do século XX; o Pibid como política de formação de professores e o Pibid como possibilidade de formação inicial e continuada ou mais um programa para a postergação de políticas efetivas para a educação. Por ser um programa relativamente novo, o Pibid apresenta temas que necessitam de maiores estudos que não serão abordados aqui, como por exemplo, suas limitações e uma avaliação de seus processos e reais impactos.

\section{2 | POLÍTICAS EDUCACIONAIS: repensando a formação de professores no início do sécu- Io XXI}

As dificuldades na tarefa de pensar e implementar políticas para uma formação docente adequada não é nova, mas uma prática recorrente da maioria dos discursos políticos educacionais e, analisando a história das lutas por uma formação docente de qualidade, verificamos que esta é uma preocupação recorrente, anunciada desde o século XVII por Comenius e após a Revolução Francesa, no século XIX, quando surgiu o problema da instrução popular, que deu início ao processo de criação de Escolas Normais encarregadas de preparar os professores, conforme salienta Saviani (2008).

A Constituição Federal de 1988, no artigo 214 determinou a criação de um Plano Nacional de Educação (PNE), de duração plurianual, para articulação e desenvolvimento do ensino em seus diversos níveis e a integração das ações do poder público (AMARAL; DOURADO, 2011). Nos dez anos seguintes, os embates se deram na definição da Lei de Diretrizes e Bases da Educação Nacional (LDB) de 1996 (Lei n 9.394/1996) e do Plano Nacional de Educação 2001-2010 (Lei nº 10.172/2001).

No início dos anos de 1990, ressurgiram no Brasil os princípios do liberalismo do século XVII, como doutrina neoliberal que direcionou politicamente o país, desencadeando a reforma do Estado que acompanhou as mudanças que aconteciam na América Latina e na Europa. Nesta década, a 
educação e a formação de professores, ganharam destaque por sua importância estratégica para a realização das reformas educativas, bem como as políticas educacionais neoliberais contribuíram para o "aprimoramento do processo de acumulação de riquezas e aprofundamento do capitalismo." (FREITAS, 2002, p. 142).

As políticas educacionais voltadas para a formação de professores, na década de 1990, tiveram seu momento de mudança quando, após oito anos de debates e tramitações aprovou-se a LDB n 9.394/1996 que estabelece no capítulo VI (Profissionais da educação), art. 62 que a formação de professores para a educação infantil e para os anos iniciais do ensino fundamental deveria acontecer no ensino superior, em licenciatura plena, em universidades e institutos superiores de educação (ISE).

A aprovação da LDB n 9.394/1996, por ter sido elaborada em governos cujas orientações eram de uma política econômica globalizada e neoliberal, trouxe diretrizes que definiam o perfil da educação no Brasil para atender as demandas de mercado.

$\mathrm{Na}$ conjuntura internacional, cujas orientações eram de uma economia globalizada e neoliberal, a LDB não poderia ser outra coisa. Ela é filha da década de 1990. Uma década marcada hegemonicamente por orientações, no plano internacional, de um modelo de política social neoliberal, que, no Brasil, vem se concretizando de vários modos, expresso em variadas reformas (previdência e do aparelho de Estado, principalmente). São dez anos em torno de um projeto de educação subsidiado por interesses políticos, sociais e econômicos, que orientam um modelo de política e de sociedade no qual se estabelece o mercado como ente regulador das políticas, da economia e da vida em sociedade (LIMA, A., 2012, p. 52-53).

Durante a década de 1990, o governo federal desenvolveu ações para a melhoria da formação de professores e valorização destes profissionais, principalmente dos professores da educação básica. Tal pensamento atribuía-se ao ter o profissional da educação como principal protagonista para melhorar a qualidade, organização e gestão do ensino nas escolas:

[...] Nessa ótica, os professores teriam um papel fundamental e a sua formação inicial e continuada passaria a se constituir numa questão de interesse do governo em todas as esferas jurídico-administrativas. Havia o reconhecimento de que a formação era necessária, de um lado, para assegurar a profissionalização e a valorização dos profissionais da educação, e, de outro lado, que teria repercussões para a melhoria dos processos escolares e de ensino-aprendizagem. (AGUIAR, 2011, p. 265).

Neste percurso, as políticas para a formação de professores continuaram alimentando o processo histórico de desvalorização social e descaso para uma formação adequada, pois a educação passou a agregar elementos constituídos por valores de mercado, princípios ressignificados. A ênfase econômica passou a legitimar um modelo de Educação como elemento de manutenção sob intervenção do Estado, em relação ao seu controle de participação, autonomia e descentralização (LIMA, A., 2012).

Sheibe (2002) esclarece que a partir da promulgação da LDB n 9.394/1996, a área da formação de professores configurou-se como tema polêmico a ser regulamentado por legislação complementar a essa lei, pois determinou a formação de professores em nível superior e criou os ISE, assim como, os cursos normais superiores, enquanto locais preferenciais para essa formação: 
mação profissional para a área da educação, que podemos denominar de "modelo dos institutos superiores de educação" no qual essa formação, embora vinculada ao ensino superior, é desvinculada do ensino universitário, passando a constituir-se numa preparação técnico-profissionalizante de nível superior. (SHEIBE, 2002, p.54).

Infere-se assim, que os ISE são diferentes das instituições universitárias, pois servem a diferentes propósitos já em essência. O modelo de formação oferecido nos ISE não tem espaço para a existência do curso de pedagogia, responsável por oferecer formação acadêmico-científica no campo educacional, o que demonstra intenção de desresponsabilizar as universidades pela formação docente, privilegiando a formação técnico-profissionalizante. Os ISE atendem a menos exigências para criação e manutenção de cursos, se comparados às universidades, as diretrizes curriculares e os parâmetros que orientam a formação de professores são diferenciados das diretrizes curriculares e parâmetros das instituições universitárias (SHEIBE, 2002).

No início do século XXI, as políticas educacionais instauradas para a formação de professores, a criação do Fundo de Manutenção do Ensino Fundamental e de Valorização do Magistério (Fundef) em 1996, a aprovação do Plano Nacional da Educação (PNE) para o período 2001-2010 e a criação do Plano de Desenvolvimento da Educação (PDE) em 2007, não mudaram os embates instaurados do que fora proposto na LDB, que não previa recursos especificamente para a formação docente. Segundo Ganzeli (2013), o Fundef, por ter tido seu investimento direcionado apenas para o ensino fundamental, bem como os vetos às metas sobre o financiamento no PNE, que minimizaram os investimentos para a formacao docente. O momento de elaboração do PNE se destacou por novos embates sobre a concepção de Sistema Nacional de Educação, consi-

derado por Saviani (2010), como a unidade de vários aspectos ou serviços educacionais reunidos para operar eficazmente o processo de educação da população. O Fórum Nacional em Defesa da Escola Pública, elaborou uma proposta de PNE após a realização de dois Congressos Nacionais de Educação, a qual foi encaminhada ao Parlamento em fevereiro de 1998. Durante este processo, o governo do presidente Fernando Henrique Cardoso (FHC) coordenou a elaboração de outra proposta de PNE, com a participação de outras instituições, do Conselho Nacional de Secretários da Educação (Consed) e da União dos Dirigentes Municipais da Educação (Undime) protocolado também, em fevereiro de 1998, gerando disputa entre as duas propostas (GANZELI, 2013).

Após dois anos de tramitação, e de disputa entre dois projetos, sendo um abrangendo os anseios da sociedade brasileira e outro contemplando os objetivos do Executivo Federal, em janeiro de 2001, o governo enviou a proposta de PNE elaborada pelo Executivo Federal ao Congresso Nacional, a qual foi tratada como prioridade de expediente, sendo aprovada em Lei $n^{\circ} 10.172$, com vigência de 2001 a 2010. Os dois projetos se diferenciavam desde sua concepção a sua aplicação, como explica Dourado (2011):

O PNE teve tramitação sui generis, envolvendo o embate entre dois projetos: o PNE da sociedade brasileira e a proposta de PNE encaminhada pelo Executivo Federal. Os dois expressavam concepções e prioridades educacionais distintas, sobretudo na abrangência das políticas, em seu financiamento e gestão, bem como no diagnóstico, nas prioridades, nas diretrizes e nas metas. (2011, p. 25, grifo do autor).

Para tanto, diante das divergências existentes nas propostas, o PNE fixou os objetivos, os meios e as condições de planejamento, por meio dos quais o poder público coordena os esforços da nação no campo educativo, na tentativa de sanar tais dificuldades propiciando: 


\begin{abstract}
[...] a elevação global do nível de escolaridade da população; a melhoria da qualidade do ensino em todos os níveis; a redução das desigualdades sociais e regionais no tocante ao acesso e à permanência, com sucesso, na educação pública e a democratização da gestão do ensino público, nos estabelecimentos oficiais, obedecendo aos princípios da participação dos profissionais da educação na elaboração do projeto pedagógico da escola e a participação das comunidades escolar e local em conselhos escolares ou equivalentes. (BRASIL, 2001).
\end{abstract}

Destaca-se no diagnóstico inicial do PNE, que deve-se primar no país pela melhoria da qualidade do ensino, a qual só poderá ser promovida juntamente com a valorização do magistério. Tal qualidade só poderá ser obtida por meio de uma política global de magistério, a qual implica a formação profissional inicial, as condições de trabalho, salário e carreira e a formação continuada, simultaneamente (BRASIL, 2001).

Com relação à formação do professor, o PNE no capítulo IV, que trata do Magistério da Educação Básica, estabelece como diretrizes para a formação dos profissionais da educação e sua valorização uma:

a) sólida formação teórica nos conteúdos específicos a serem ensinados na Educação Básica, bem como nos conteúdos especificamente pedagógicos;

b) ampla formação cultural;

c) atividade docente como foco formativo;

d) contato com a realidade escolar desde o início até o final do curso, integrando a teoria à prática pedagógica;

e) pesquisa como princípio formativo;

f) domínio das novas tecnologias de comunicação e da informação e capacidade para integrá-las à prática do magistério;

g) análise dos temas atuais da sociedade, da cultura e da economia;

h) inclusão das questões relativas à educação dos alunos com necessidades especiais e das questões de gênero e de etnia nos programas de formação;

i) trabalho coletivo interdisciplinar;

j) vivência, durante o curso, de formas de gestão democrática do ensino;

k) desenvolvimento do compromisso social e político do magistério; e

I) conhecimento e aplicação das diretrizes curriculares nacionais dos níveis e modalidades da educação básica. (BRASIL, 2001).

Diante dessas diretrizes para a formação de professores, o PNE propõe a melhoria da formação docente por meio de formação cultural com foco na formação para a docência, introdução do licenciando no âmbito escolar desde o início da vida acadêmica, vinculação do ensino à pesquisa, integração e domínio das tecnologias de informação e comunicação ao magistério e inclusão de assuntos referentes a vivências na sociedade. O PNE põe em pauta problemas históricos da formação docente e também fixa prioridades, segundo o dever constitucional e as necessidades sociais propondo garantias como:

1. Garantia de ensino fundamental obrigatório de oito anos a todas as crianças de 7 a 14 anos, assegurando o seu ingresso e permanência na escola e a conclusão desse ensino.

2. Garantia de ensino fundamental a todos os que a ele não tiveram acesso na idade própria ou que não o concluíram.

3. Ampliação do atendimento nos demais níveis de ensino - a educação infantil, o ensino médio e a educação superior.

4. Valorização dos profissionais da educação.

5. Desenvolvimento de sistemas de informação e de avaliação em todos os níveis e modalida- 
des de ensino, inclusive educação profissional, contemplando também o aperfeiçoamento dos processos de coleta e difusão dos dados, como instrumentos indispensáveis para a gestão do sistema educacional e melhoria do ensino. (BRASIL, 2001).

Nesse sentido, podemos inferir que o PNE 2001/2010, definiu bases para a formação de professores, estabeleceu garantias para o atendimento às demandas sociais e para formação dos profissionais da educação, com objetivos e metas que indicaram a necessidade de: levantamento de dados; mapeamento dos professores sem habilitação; organização e estabelecimento de diretrizes; currículos e programas de formação inicial e continuada de professores; estabelecimento de diretrizes e parâmetros curriculares para os cursos superiores de formação docente para os diferentes níveis e modalidades; estabelecimento de cursos de nível médio para preparar pessoal qualificado para a educação infantil; ampliação dos programas de formação em serviço; desenvolvimento de programas de educação à distância; cursos de formação para professores por parte das universidades; cursos de formação no interior dos Estados; cursos de especialização para a formação nas diferentes áreas de ensino; ampliação da oferta de mestrado, doutorado e pesquisa.

Verifica-se assim, a definiçao de várias metas a serem cumpridas em prol da formação de professores, no entanto, o cumprimento destas metas estabelecidas exigiam a definiçao de outras políticas, ações e programas do governo para que fossem regulamentadas, o que não se efetivou totalmente. Dentre as leis criadas para regulamentar o PNE 2001/2010, vale a pena citar o Plano de Desenvolvimento da Educação (PDE) em 2007, que coloca à disposição dos estados e municípios, instrumentos para avaliação e implementação de políticas de melhoria da qualidade da educação (BRASIL, 2007b).

Em 2007, por meio do Decreto $n^{\circ}$ 6.094/2007, instituiu-se o Plano de Metas Compromisso Todos pela Educação (Plano de Metas), um programa do PDE, que objetiva melhorias dos indicadores educacionais por meio de regime de colaboração entre os entes federados, com 28 diretrizes consolidadas em um plano de metas, que visa a manutenção e desenvolvimento da educação básica. Na tentativa de efetivar este regime de colaboração, o governo federal também em 2007, lançou o Plano de ações Articuladas (PAR) (BRASIL, 2007), este que nasceu do Plano de Metas e foi lançado concomitantemente ao PDE, sendo um instrumento para o planejamento de políticas educacionais, comandas pelo Ministério da Educação, aos entes federados que aderiram ao Plano de Metas:

Art. $9^{\circ}$ O PAR é o conjunto articulado de ações, apoiado técnica ou financeiramente pelo Ministério da Educação, que visa o comprimento das metas do Compromisso e a observância das suas diretrizes.

Art. 10. O PAR será base para termo de convênio ou de cooperação, firmado entre o Ministério da Educação e o ente apoiado. (BRASIL, 2007a).

No PAR, após aderirem ao Plano de Metas, os estados e municípios realizam um diagnóstico da realidade educacional local e, a partir deste, desenvolvem um conjunto de ações estruturadas em quatro dimensões: Gestão Educacional; Formação de Professores e dos Profissionais de Serviço e Apoio Escolar; Práticas Pedagógicas e Avaliação e Infraestrutura Física e Recursos Pedagógicos.

Essa configuração da política educacional refletiu na elaboração do Plano Plurianual (PPA), que visa "à elevação da qualidade da educação" e reitera o compromisso criado entre o PDE e o PAR, para atender à demanda por formação inicial e continuada de professores da educação básica, oferecida pelas redes públicas de ensino de todo país, de acordo com o informado previamente por cada estado. 
O PIBID NO BOJO DAS POLÍTICAS | Josiane Lopes Medeiros e Luciene Lima de Assis Pires

Ao analisar as metas sobre formação de professores e dos profissionais de serviço e apoio escolar, assim como da proposta de elaboração de PPA constata-se que:

\begin{abstract}
As ações vinculadas ao PAR visam atender a demanda por formação dos profissionais da educação básica, com a oferta de cursos de formação inicial e continuada de acordo com a demanda identificada em cada estado, mediante adesão dos gestores locais. Com o PDE e o PAR, há uma nova configuração da política educacional que 'reflete-se no PPA 2008-2011, na reestruturação de seus programas em relação aos que existiam no PPA precedente'. Os programas concernentes aos profissionais da educação integram este processo. (AGUIAR, 2011, p. 271-272).
\end{abstract}

Neste sentido, a fim de valorizar a formação dos profissionais da educação e atender ao proposto no PNE 2001/2010 e nos planos, programas e propostas dele advindos, o Governo Federal implementou em 2007, a partir do PDE, o Pibid, sendo parte de um dos investimentos voltados para a formação e valorização dos profissionais da educação, os quais não constavam no PPA 2004-2007 e passaram a integrar os programas de formação no PPA 2008-2011, que defendiam que para se ter a elevação da qualidade do ensino na educação, precisa-se de professores competentes. Para tanto, em 2008, a formação de professores teve um importante reforço com a incorporação da Coordenação da Política de Formação de Professores da Educação Básica pela Coordenação de Aperfeiçoamento de Pessoal de Nível Superior (Capes), ampliando o Pibid lançado em 2007 com um duplo objetivo: promover a aproximação entre a universidade e as escolas e tornar a sala de aula parte da formação para o magistério (BRASIL, 2014).

\title{
3 | O PIBID COMO POLÍTICA DE FORMAÇÃO DE PROFESSORES
}

A formação de professores tem sido desafiante no contexto das Instituições de Ensino Superior (IES), já que estas demonstram diferentes linhas de pensamento, sendo frequentemente cri-

ticadas e questionadas sobre a qualidade e formação inicial do docente, tornando-se necessário um aprofundamento teórico sobre autores que debatem esta temática. Imbernón (2004), afirma que a formação docente como um dos elementos essenciais para o desenvolvimento profissional do professor, não pode ser vista apenas como desenvolvimento pedagógico, teórico e cognitivo, a formação de professores, também é incrementada por uma situação profissional que envolve diversos fatores, dentre eles o salário, a valorização, o clima do trabalho, a demanda de mercado, a promoção, as hierarquias, a carreira docente e a formação permanente.

As instituições formadoras têm o pensamento formado por uma visão empírica e tecnicista, visão esta que por vezes impede, desmerece e desestimula práticas inovadoras; o apoio pe-

dagógico como instrumento de acesso a novas metodologias; amparo ao professor e renovação e atualização da didática; momentos de formação e planejamento aos docentes por traduzirem esta como dispensável. Vasconcelos (2009, p. 66), destaca que "a universidade deve criar um espaço que possibilite a seus docentes a reflexão sobre sua própria prática, visando, com isso, à melhoria da qualidade pedagógica de todos os seus cursos e de seus professores em exercício", afirmando também, sobre a necessidade de se investir tempo, esforço e recursos em programas voltados para a capacitação e desenvolvimento de recursos humanos.

Nesse sentido, o Pibid criado em dezembro de 2007, gerenciado pelo Departamento de Educação Básica (DEB) da Capes, concede bolsas de iniciação à docência para alunos de licenciaturas das IES em diversas áreas (sendo que no projeto inicial a prioridade seria para as áreas de Física, Química, Biologia e Matemática, devido a carência de profissionais nessas disciplinas no ensino médio), por meio de parcerias com escolas de educação básica da rede pública de ensino. 
O Pibid apresenta o compromisso de fomentar a iniciação à docência, valorizar o magistério, contribuir com a melhoria da Educação Básica e elevar o Índice de Desenvolvimento da Educação Básica (IDEB) encontrando-se assim, no âmbito do PDE (BRASIL, 2014).

O Pibid tem como finalidade inserir o licenciando desde o início de sua formação acadêmica na realidade escolar, propiciando este contato com a futura profissão e as possibilidades concretas de exercer a docência, com criatividade, participando de experiências metodológicas, tecnológicas e práticas docentes de caráter inovador e interdisciplinar, buscando a superação de problemas identificados no processo de ensino-aprendizagem, propiciando aos licenciandos, experiências pedagógico-formativas, onde possam articular sua formação na universidade com a realidade escolar (CARVALHO; QUINTEIRO, 2013).

Segundo o Relatório de Gestão da DEB/ 2009-2013 da Capes (2014), o Pibid se diferencia do estágio por ser uma proposta extracurricular, com carga horária maior que a estabelecida pelo Conselho Nacional de Educação (CNE) para o estágio e por inserir os licenciandos desde o início da graduação no ambiente escolar, se assim as IES definirem em seu projeto. A presença dos bolsistas nas escolas não tem caráter de observação, como no estágio, mas sim orgânica. $A$ vivência de múltiplos aspectos pedagógicos contribui para a formação dos futuros professores.

Dentre os objetivos do Pibid, destacam-se os que primam pela formação docente: contribuir para elevar a qualidade dos cursos de formação de educadores, melhorar a formação inicial dos licenciandos, aperfeiçoar a formação de professores para a educação básica, contribuir para a articulação entre teoria e prática, necessárias à formação de professores e para a melhoria de qualidade da educação pública brasileira (BRASIL, 2014).

O Pibid atende projetos aprovados por meio de editais lançados pela Capes e enviados pelas IES públicas e privadas, com e sem fins lucrativos, que tenham licenciaturas, sendo concedidas cinco modalidades de bolsas como forma de incentivo à participação: aos estudantes de cursos de licenciatura que desenvolvam atividades pedagógicas em escolas da rede pública de educação básica; ao coordenador institucional que articula e implementa o programa nas IES; aos coordenadores de área envolvidos na orientação aos bolsistas e, ainda, aos docentes de escolas públicas, responsáveis pela supervisão dos licenciandos. Também são repassados recursos de custeio para execução de atividades vinculadas ao projeto (BRASIL, 2014).

Em ação conjunta do Ministério da Educação, por intermédio da Secretaria de Educação Superior (Sesu), da Capes e do Fundo Nacional de Desenvolvimento da Educação (FNDE), foi lançado o Edital MEC/CAPES/FNDE, em 12 de dezembro de 2007, que operacionalizou o Pibid, tornando público a chamada que atendeu instituições federais de ensino superior e centros federais de educação tecnológica, com avaliação satisfatória obtida por seus cursos de licenciatura presencial, no Sistema Nacional de Avaliação da Educação Superior (Sinaes), os quais haviam firmado convênio ou acordo de cooperação com escolas públicas de Educação Básica dos municípios, dos estados ou do Distrito Federal (BRASIL, 2014).

Embora o Pibid tenha sido lançado em 2007, o programa passa a ser implementado de fato, somente em 2009, ano em que por meio da Portaria $n^{0} 122 / 2009$, o programa passa a ser atendido no âmbito da Capes, com vistas à melhorias de implantação e estruturação do programa. Nesse mesmo ano, por meio do Edital Capes $n^{\circ} 2 / 2009$, ampliou-se a participação das instituições, estendendo às instituições públicas de educação superior estaduais, acrescentando o atendimento a toda a educação básica, educação especial, educação de jovens e adultos, educação básica oferecida nas comunidades quilombolas, indígenas e no campo. A recomendação dada às IES participantes, foi de que os projetos do Pibid fossem desenvolvidos em escolas que obtiveram notas abaixo da média geral no IDEB, como por exemplo, nas escolas com experiências bem sucedidas de ensino e aprendizagem, contribuindo para a elevação do IDEB e aproximando do 
índice considerado no Plano de Metas Compromisso Todos pela Educação, média 6,0.

Mediante o crescente interesse das instituições no programa, em 2010, lançou-se o Edital Capes $n^{0}$ 18/2010 ampliado para atender instituições municipais públicas, universidades e centros universitários filantrópicos, confessionais e comunitários de educação superior, sem fins lucrativos. Com vistas a atender diferentes públicos e trabalhos voltados à educação indígena e educação rural, em 2010, lançou-se também o Edital Conjunto $n^{\circ} 2 / 2010$ que contemplava projetos à docência para a diversidade, em parceria com a Capes, por meio do Programa de Iniciação à Docência para a Diversidade (Pibid) e Secretaria de Educação Continuada, Alfabetização e Diversidade (Secad). O Edital Conjunto $n^{\circ} 2 / 2010$, foi direcionado para alunos matriculados em instituições participantes do Programa de Apoio à Formação Superior em Licenciaturas Indígenas (Prolind), Programa de apoio à Formação Superior em Licenciatura em Educação do Campo (Procampo) e para coordenadores e supervisores responsáveis institucionalmente pelo Pibid.

O Pibid Diversidade dentre seus objetivos, prima pelo aperfeiçoamento da formação inicial de professores para as escolas indígenas e para as escolas do campo, com metodologias que atendam à diversidade intercultural e linguísticas, considerando as diferenças culturais, a interculturalidade do país e suas implicações para o trabalho pedagógico (BRASIL, 2014). Em 2011, mediante uma reestruturação do MEC, dentre outras mudanças, extinguem-se dois departamentos: a Secretaria de Educação a distância (Seed) e a Secretaria de Educação Especial (Seesp), incorporando os programas de inclusão à nova Secretaria de Educação Continuada, Alfabetização, Diversidade e Inclusão (Secadi), substituindo a secretaria anterior, Secad, que não abrangia a promoção da educação inclusiva.

No início de 2011, pelo Edital Capes n 1/2011, o Pibid estendeu a possibilidade de envio de projetos por todas as instituições públicas de ensino superior, sendo atendidas naquele ano, 146 instituições das cinco regiões do país, em um total de aproximadamente 30.000 bolsas distribuídas entre licenciandos, professores e coordenadores. Com a preocupação de avaliar as ações e implementação do Pibid, a Capes já havia realizado em outubro de 2009 o I Encontro Nacional do Pibid e, em setembro de 2011, promoveu o II Encontro Nacional de Coordenadores Institucionais do Pibid, cujo objetivo foi de proporcionar a troca de experiências, avaliar os resultados alcançados e discutir propostas de melhorias para o programa (BRASIL, 2014).

Em atendimento às IES que desejavam participar do Pibid, o Edital Capes n 11/2012, possibilitou a participação de novas IES, passando a atender 195 instituições, abrigando mais de 280 projetos, concedendo aproximadamente 19.000 novas bolsas de iniciação à docência para alunos de cursos de licenciaturas, professores e coordenadores participantes do Pibid, totalizando mais de 49.300 bolsas, tendo um aumento de $64,37 \%$ em relação ao concedido em 2011 , segundo dados publicados pelas Capes. Nesta edição do programa, poderiam participar IES federais, estaduais, municipais, instituições comunitárias, confessionais, filantrópicas, privadas sem fins lucrativos, participantes de programas do MEC como o Programa de Apoio de Reestruturação e Expansão das Universidades Federais (Reuni), o Exame Nacional de Desempenho de Estudantes (Enade), o Plano Nacional de Formação para o Magistério da Educação Básica (Parfor) e a Universidade Aberta do Brasil (UAB) (BRASIL, 2013).

Segundo informações do Relatório de Gestão da Diretoria de Formação de Professores da Educação Básica (DEB) de 2009-2013, a CGV/DEB/CAPES lançou dois editais em 2013, sendo o primeiro $n^{\circ} 061 / 2013$ e o segundo $n^{\circ}$ 066/2013. O primeiro possibilitou a todas as instituições apresentarem suas propostas, diferenciando-se dos demais editais, por abranger e alcançar as instituições de ensino superior: públicas, privadas sem fins lucrativos e alunos do Programa Universidade para Todos (ProUni). O segundo edital convocou as instituições que possuem cursos de licenciatura intercultural, indígena e do campo. Tais editais, selecionaram mais de 300 projetos 
e ultrapassou em mais de 15.000 bolsas o quantitativo esperado de 75.000 concessões, as quais foram concedidas em 2014. Neste mesmo ano, o Pibid passou por uma reorganização em sua gestão de modo que a Capes pôde avançar na análise dos relatórios, no cumprimento dos objetivos e na socialização dos resultados, promovendo assim, uma reformulação das normas do Pibid, para que estas possam suportar sua expansão e manter a qualidade dos projetos para a formação de professores.

Assim sendo, face aos resultados obtidos, a abrangência do programa e novas perspectivas, o Pibid tornou-se um programa permanente, devido à credibilidade alcançada, em 04 de abril de 2013, pela Lei $n^{\circ} 12.796$ que alterou a LDB/1996, para dispor sobre a formação dos profissionais da educação e dar outras providências, incluindo então, a iniciação à docência como ação permanente do MEC, passando de política de governo para política de Estado como estabelece o parágrafo $5^{\circ}$ da LDB/1996:

§ $5 \circ$ A União, o Distrito Federal, os Estados e os Municípios incentivarão a formação de profissionais do magistério para atuar na educação básica pública mediante programa institucional de bolsa de iniciação à docência a estudantes matriculados em cursos de licenciatura, de graduação plena, nas instituições de educação superior. (BRASIL, 2013, grifo nosso).

Com a inclusão do programa de iniciação à docência na LDB/1996, e com os investimentos feitos pelo governo, em dezembro de 2013 o III Seminário Nacional do Pibid, promoveu um debate de caráter teórico, crítico e cultural relacionado à constituição da identidade do professor, com ênfase nas complexidades e paradoxos que marcam a realização desse ato na contemporaneidade (BRASIL, 2013). Neste seminário também foram discutidas ações com os impactos esperados para 2014, tais como: intencionalidade pedagógica da formação e impactos do Pibid; apresentação da nova portaria do Pibid; sistema de prestação de contas; programas MEC; gestão do programa, administração das bolsas e relação institucional; panorama da formação de professores na atualidade e discussão sobre a criação do Fórum dos Coordenadores Institucionais do Pibid (FORPIBID) (BRASIL, 2014).

Em 2014, segundo informações da Capes, foi concedido pelos editais do Pibid e Pibid Diversidade selecionados em 2013, mais de 90.000 bolsas, representando um aumento de $2.814 \%$ em comparação a 2007, segundo dados publicados pela Capes. As bolsas disponibilizadas foram distribuídas entre: iniciação à docência, supervisão, coordenação de área, coordenação de área de gestão e coordenação institucional, entre as IES cadastradas.

\section{4 | PIBID: possibilidade de formação inicial e continuada ou mais um programa para a pos- tergação de políticas efetivas para a educação?}

Segundo a Capes, os princípios pedagógicos que norteiam o Pibid são embasados nos estudos de Antônio Nóvoa ${ }^{1}$ para a formação e desenvolvimento profissional de professores que referência a formação no trabalho, na escola e na vivência concreta de fatos; uma formação combinada com o conhecimento teórico e metodológico dos professores das IES com o conhecimento prático dos professores da educação básica; formação docente atenta às múltiplas faces do

\footnotetext{
${ }^{1}$ António Manuel Seixas Sampaio da Nóvoa é educador português e reitor da Universidade de Lisboa. É doutor em Ciências da Educação e Doutor em História. É considerado um dos maiores especialistas mundiais em formação de professores e tem mais de 150 títulos entre livros e artigos de sua autoria, publicados em doze países.
} 
O PIBID NO BOJO DAS POLÍTICAS | Josiane Lopes Medeiros e Luciene Lima de Assis Pires

cotidiano escolar; formação de professores realizada com diálogo e trabalho coletivo (BRASIL, 2014).

Estes princípios nortearam os objetivos do Pibid que reconhecem o valor da escola e da formação de seus professores com suas especificidades. Portanto, o Pibid procura atender baseado nestes princípios pedagógicos, ações voltadas "para o humano, para as práticas que cultivem os valores sociais, éticos, estéticos e educacionais da sociedade brasileira." (BRASIL, 2014, p. 72).

A formação docente proposta pelo Pibid tem como finalidade: indução e fomento da formação inicial e continuada dos profissionais do magistério, articulação entre os sistemas de ensino e estímulo à valorização docente em todos os níveis e modalidades. Sendo assim o Pibid atende a perspectiva de proporcionar o quanto antes, a inserção do licenciando na escola, visto que, contribui com sua formação inicial, possibilita que seja experienciado seu futuro ambiente de trabalho e seu reconhecimento como integrante do processo de busca pela qualidade do ensino.

O governo estabelece programas de formação de professores inicial e continuada, na tentativa de reaver o que fora perdido por ele mesmo, em razão dos anos de descaso e ausência de investimentos, que contribuíram para o desinteresse dos jovens pela docência já no ensino médio, o que consequentemente colaborou com a carência de docentes para a educação básica e para as licenciaturas, colocando o país em desvantagem em relação a outros países, pois isto implica em diminuição nos índices educacionais. O Pibid, como uma política indutora do governo, reconhece a necessidade de investir na formação de professores, na perspectiva de integrar-se a um conjunto de ações que visam à formação inicial, continuada e permanência na docência, junto aos estudantes, contribuindo para a elevação dos processos de aprendizagem de alunos, elevação do IDEB, além de proporcionar uma possibilidade promissora de estabelecer compromissos para a construção de relações produtivas e efetivas para a docência

O Pibid pode ter contribuído em alguns aspectos com as questões da formação docente, porém, não se pode desconsiderar a necessidade de uma avaliação profunda em seus interesses, investimentos e resultados. Mesmo sendo agora um programa de Estado, o Pibid foi pensado e implementado como um programa de governo, e por isso traz em seu bojo intencionalidades e parcialidades. Inicialmente, se trata de um programa emergencial que visa atender à falta de professores em disciplinas específicas da educação básica, demonstrando com isso, que algo deixou de ser feito em tempo hábil para ser atendido somente agora.

Segundo os dados apresentados pela Capes, o Pibid teve um crescimento significativo num curto espaço de tempo com uma evolução considerável. De acordo com Silva (2013), o Pibid tem suas contribuições e potencialidades no que diz respeito a desafios, construções de novos horizontes e perspectivas, porém, é de sumo importância que seja feita uma avaliação profunda sobre o programa, suas ideologias, seu desenvolvimento, sua finalidade, aceitação e participação de professores, alunos e gestores.

O Pibid traz consigo reflexos de políticas imediatistas, assistencialistas, carregado de interesses que contribuem para a manutenção e continuidade de políticas neoliberais, que não demonstram preocupação com uma formação docente adequada bem como plano de carreira, salários e a devida valorização de seus profissionais.

Analisando os objetivos do Pibid e em especial os que primam pela formação docente, já citados anteriormente neste artigo, nos questionamos se estes cumprem a função que nos é apresentada. Como o Pibid pode contribuir para elevar a qualidade dos cursos de formação de educadores se estes licenciandos são formados em instituições, no qual, muitas vezes não se tem a devida valorização de seus profissionais? E quando estes alunos vão para as escolas e convivem com a situação crítica em que muitas estão inseridas, no abandono e escassez de quase tudo, estas situações "contribuem para fomentar revisões teóricas, atitudinais e práticas necessárias 
a inovações efetivas e fecundas no modo de conceber e viver a docência?" (FARIAS; ROCHA, 2012, p. 47).

\begin{abstract}
[...] a concretização de uma sólida política de valorização dos profissionais da educação não pode ser concebida e construída sem uma consistente política de formação desses profissionais. Uma política de formação que se sustente em uma sólida fundamentação teórica, que articule teoria e prática, formação inicial e formação continuada, e que vá além da multiplicação desarticulada de cursos e ações de formação. (SILVA, 2013, p. 176-177).
\end{abstract}

Nesse sentido, é preciso dar a devida atenção e saber analisar as proposituras das ações que estão sendo implementadas pelo governo federal, com faces a uma política nacional para a formação docente e valorização do magistério, para que se perceba em que medidas tais ações caminham na direção apontadas pelas diretrizes de valorização e da carreira docente (SILVA, 2013).

Dentre as limitações do Pibid, Soczek (2011) destaca que em muitas escolas, a comunidade escolar e os próprios pibidianos confundem sua função e suas ações do programa com a função e ações do estágio, intencionalmente ou não, e em alguns momentos veem o pibidiano como "recurso humano disponível" na falta de algum professor. Diante desses fatos, como o Pibid alcançará um de seus objetivos que é a melhoria da qualidade da educação pública brasileira, se ainda há dúvidas primárias quanto a propositura do programa entre os seus envolvidos.

Entre indagações e reflexões, dúvidas e conquistas, quando paramos para ir às raízes e determinantes da questão vemos que o PIBID em relação ao Estágio e as Práticas de Ensino, mesmo que aparentemente semelhantes, pertencem a campos de poder, estrutura, funcionamento e condições objetivas diferentes. (LIMA, M., 2012, p. 244).

Contribuir com a melhoria da qualidade da educação pública, é possível por meio da valorização das licenciaturas, tornando-as atrativas e competitivas com outras profissões de mesma titulação, com salários e valorização social do papel do professor. Também, se faz necessário à reorganização da proposta do ensino médio, bem como ações em prol das condições de trabalho nas escolas que não são atrativas, "podendo, inclusive, 'espantar' o aspirante a professor" (SOCZEK, 2011, p. 10).

\title{
5 | CONSIDERAÇÕES FINAIS
}

Acredita-se que a formação de professores é um instrumento importante para a educação. Espera-se que os professores tenham formação em nível superior obtidas em instituições preparadas, porém, a realidade mostra salas de aulas regidas por professores com formação precária, sem habilitação adequada para tal ofício. É preciso defender a formação de professores em condições adequadas, com reconhecimento de seu trabalho tanto na perspectiva acadêmica, social e financeira, quanto na valorização do magistério e da pessoa do professor. Programas dessa natureza, como o Pibid, com compensação em forma de bolsas para professores e alunos, a fim de se obter melhores resultados, não seriam necessários se tivéssemos políticas públicas que garantissem tais aspectos.

O governo deve aprimorar a formação docente com adequadas condições de trabalho, salários dignos, valorização do magistério e da formação de professores. A partir do momento em que se tem de oferecer incentivos, percebe-se o descaso que a longo tempo a educação e seus profissionais vêm sendo submetidos. 
O Pibid tem possibilidades, mas há limites e questões a serem melhorados e avaliados, por exemplo: só participa uma parcela dos alunos de um curso, com isso, nem todos têm acesso. Os professores tanto orientadores quanto supervisores, geralmente não têm tempo em sua carga horária para o trabalho que se faz necessário ao programa, sendo assim, a bolsa recebida significa mais um aumento de sua carga horária de trabalho, do que efetivamente uma proporção adequada ao trabalho de planejamento, acompanhamento, encontros e avaliações das atividades (SOCZEK, 2011).

Melhorar a formação inicial dos licenciandos é uma necessária iniciativa já que uma parte da qualidade da educação depende do trabalho dos professores. Observa-se na história das políticas educacionais voltadas para a formação de professores, a descontinuidade das propostas, o descaso e o abandono que muitas vezes são tratadas tais políticas, comprovados pela falta de investimentos e prioridade de pauta, principalmente quando se refere a docência para a educação básica.

Para que essas lacunas sejam superadas, se faz necessário que aconteçam as trocas de experiências, os diálogos e os momentos de estudos, os quais o Pibid se propõe a fazer na intenção de contribuir com a formação inicial e continuada. Para tanto, é importante fomentar estratégias de trabalhos de colaboração entre os pares, que reúnam professores de diferentes áreas para trabalhar em conjunto, discutindo práticas, intenções, dificuldades e possibilidades do processo formativo, certos de um espaço de formação pedagógica dinâmica para estes professores (FARIAS; ROCHA, 2012).

O programa está ancorado na oferta de bolsas, mas é preciso pensar, como será a sua continuidade sem essa política de incentivo. A iniciativa do governo com o Pibid colabora em alguns fatores da educação e do ensino, porém, esta não basta somente com iniciativas e investimentos pontuais que postergam ações efetivas, mas sim, com a concretização de políticas permanentes que são imprescindíveis a serem investigadas posteriormente. 


\section{Referências}

AGUIAR, Márcia Angela da S. A formação dos profissionais da educação no contexto atual e o PNE 20112020: avaliação e perspectivas. In: DOURADO, Luiz Fernandes (Org.). Plano Nacional de Educação (20112020): avaliação e perspectivas. 2. ed. Goiânia: Ed. da UFG; Belo Horizonte: Autêntica, 2011. p. 285-315.

AMARAL, Nelson Cardoso; DOURADO, Luiz Fernandes. Financiamento e gestão da educação e o PNE 2011-2020: avaliação e perspectivas. In: DOURADO, Luiz Fernandes (Org.). Plano Nacional de Educação (2001-2010): avaliação e perspectivas. 2. ed. Goiânia: Editora UFG; Belo Horizonte: Autêntica Editora, p. 285315, 2011.

BRASIL. Ministério da Educação. Coordenação de Aperfeiçoamento de Pessoal de Nível Superior. Pibid. Educação básica. Brasília, DF, 2014. Disponível em: <http://www.capes.gov.br/educacao-basica/55-educacao-basica-s/conteudo-eb>. Acesso em: 04 mar. 2013.

Constituição (1988). Constituição da República Federativa do Brasil. Brasília, DF: Senado Federal, 1988.

Decreto-lei $n^{\circ}$ 6.094, de 24 de abril de 2007. Dispõe sobre a implementação do Plano de Metas Compromisso Todos pela Educação e dá outras providências. Brasília, DF, 2007a.

Lei $n^{\circ} 10.172$, de 9 de janeiro de 2001. Estabelece o Plano Nacional de Educação. Brasília, DF, 10 jan. 2001.

. Lei no 12.796, de 4 de abril de 2013. Altera a Lei $\mathrm{n}^{\circ}$ 9.394, de 20 de dezembro de 1996, que estabelece as diretrizes e bases da educação nacional, para dispor sobre a formação dos profissionais da educação e dar outras providências. Brasília, DF, 2013.

Lei $n^{\circ}$ 9.394, de 20 de dezembro de 1996.

Estabelece as Diretrizes e Bases da Educação Nacional. Brasília, DF, 1996.

Ministério da Educação. O plano de desenvolvimento da educação: razões, princípios e programas. Brasília, DF, 2007b.

CARVALHO, Diana Carvalho de; QUINTEIRO, Jucirema. A formação docente e o Pibid: dilemas e perspectivas em debate. Entrever, Florianópolis, v. 3, n. 4, p. I-XII, jan./jun. 2013.
DOURADO, Luiz Fernandes. Plano Nacional de Educação como política de Estado: antecedentes históricos, avaliação e perspectivas. In: DOURADO, Luiz Fernandes (Org.). Plano Nacional de Educação (20112020): avaliação e perspectivas. 2. ed. Goiânia: Ed. da UFG; Belo Horizonte: Autêntica, 2011. p. 17-59.

FARIAS, Isabel Maria Sabino de; ROCHA, Cláudio César Torquato. Pibid: uma política de formação docente inovadora? Revista Cocar, Belém, v. 6, n. 11, p. 41-49, jan./jul. 2012.

FREITAS, Helena Costa Lopes de. Formação de professores no Brasil: 10 anos de embates entre projetos de formação. Educação e Sociedade, Campinas, v. 23, n. 80 , p. $136-167$, set. 2002

GANZELI, Pedro. Regime de colaboração e plano nacional de educação: política de estado ou política de governo. In: CALDERÓN, Adolfo Ignácio et al.(Org.). Políticas e gestão da educação: desafios em tempos de mudanças. Campinas, SP: Autores Associados, 2013. p. $45-64$.

IMBERNÓN, Francisco. Formação docente e profissional: formar-se para a mudança e a incerteza. 4. ed. São Paulo: Cortez, 2004.

LIMA, Antonio Bosco de. Dez anos de LDB: anos de contínua reforma educacional. In: MARQUES, Mara Rúbia Alves; SILVA, Maria Vieira (Org.). LDB: balanços e perspectivas para a educação brasileira. 2. ed. Campinas, SP: Alínea, 2012. p. 51-69.

LIMA, Maria do Socorro Lucena. A prática de ensino, o estágio supervisionado e o Pibid: perspectivas e diretrizes para os cursos de licenciatura. In: ENCONTRO NACIONAL DE DIDÁTICA E PRÁTICAS DE ENSINO, 16. 2012, Campinas. Anais... Campinas: UNICAMP, 2012. p. 234-246. Livro 2.

SAVIANI, Dermeval. A pedagogia no Brasil: história e teoria. Campinas, SP: Autores Associados, 2008. (Coleção memória da educação).

PDE- Plano de Desenvolvimento da Educação: análise crítica da política do MEC. Campinas, SP: Autores Associados, 2009. (Coleção polêmicas do nosso tempo, 99). 
O PIBID NO BOJO DAS POLÍTICAS | Josiane Lopes Medeiros e Luciene Lima de Assis Pires

\section{Referências}

Sistema Nacional de Educação articulado ao Plano Nacional de Educação. Revista Brasileira de Educação, Brasília, DF, v. 15, n. 44, p. 380-393, maio/ ago. 2010.

SHEIBE, Leda. Formação dos profissionais da educação pós-LDB: vicissitudes e perspectivas. In: VEIGA, Ilma Passos Alencastro; AMARAL, Ana Lúcia (Org.). Formação de professores: políticas e debates. Campinas, SP: Papirus, 2002. p. 47-63. (Coleção magistério: formação e trabalho pedagógico).

SILVA, Marcelo Soares Pereira da. Políticas de formação e valorização dos profissionais da educação básica em questão: contradições e inquietações. In: CALDERÓN, Adolfo Ignácio et al. (Org.). Políticas e gestão da educação: desafios em tempos de mudanças. Campinas, SP: Autores Associados, 2013. p. 165-198.
SOCZEK, Daniel. PIBID como formação de professores: reflexões e considerações preliminares. Revista Formação Docente, v. 3, n. 5, ago./dez. 2011.

VASCONCELOS, Maria Lucia M. Carvalho. A formação do professor do ensino superior. Niterói: Intertexto; São Paulo: Xamã, 2009. 